\title{
Algumas considerações sobre as noções de verdade e mentira no pensamento de Nietzsche e Freud
}

\author{
Some considerations about the notions of truth and lie in Nietzsche's and \\ Freud's thought
}

MICHAELLA CARLA LAURINDO ${ }^{1}$

WILSON ANTONIO FREZZATTI JUNIOR ${ }^{2}$

\begin{abstract}
Resumo: O presente trabalho visa tecer algumas considerações sobre as noções de verdade e mentira na obra de Friedrich Nietzsche e Sigmund Freud. A obra que suscitou esse questionamento foi "Sobre Verdade e Mentira no sentido extra moral", um texto que foi ditado por Nietzsche a um amigo em 1873, mas só publicado postumamente. O filósofo alemão critica o fato do homem moderno confiar no poder das palavras e dos conceitos sem atentar que não portam um significado unívoco e muito menos conduzem à uma verdade universal. Já Freud assevera que não há a realidade dos fatos, o que o ser humano nomeia como "a verdade" é determinada pela sua realidade psíquica. Mas a realidade psíquica carece de essência e nada mais é do que uma tentativa defensiva, no intuito de preencher com algum sentido a existência - sentida como árdua justamente pela sua falta de sentido.
\end{abstract}

Palavras-Chave: Verdade. Mentira. Nietzsche. Freud

Abstract: The present work aims to make some considerations about the notions of Truth and Lie in the work of Friedrich Nietzsche and Sigmund Freud. The work that raised this question was "About Truth and Lie in the extra moral sense", a text that was said by Nietzsche to a friend in 1873 , but only published posthumously. The German philosopher criticizes the fact that modern man relies on the power of words and concepts without realizing that they do not carry a single meaning and much less lead to a universal truth. Freud, on the other hand, asserts that there is no reality of the facts, what the human being calls "the truth" is determined by his psychic reality. But the psychic reality lacks essence and is nothing more than a defensive attempt, in order to fill existence with some meaning felt as arduous precisely because of its meaninglessness.

Keywords: Truth. Lie. Nietzsche. Freud

\section{Verdade e Mentira em Nietzsche}

Para Nietzsche, a verdade está intrinsecamente ligada a esfera moral, pois as investigações históricas apontam que só tardiamente a verdade começa a integrar o campo da lógica e do conhecimento. Ele inicia argumentando que não há uma adequação entre as palavras e as coisas, pois a palavra já é o estímulo nervoso transformado em imagem e que por sua vez é transformado em som. A palavra surge a partir da "afiguração de um estímulo nervoso em sons", se trata de um ato completamente subjetivo. "[...] um estímulo nervoso, primeiramente transposto em

\footnotetext{
${ }^{1}$ Discente do curso de Filosofia da Unioeste. E-mail: michaella.laurindo@pucpr.br

2 Orientador deste trabalho, professor do curso de Filosofia da Unioeste. E-mail: wfrezzatti@uol.com.br
} 
uma imagem! Primeira metáfora. A imagem, por sua vez, modelada em um som! Segunda metáfora" (NIETZSCHE, 2012, p. 32). Se o estímulo nervoso é anterior à palavra, não há como ela corresponder às coisas. Dessa forma, os conceitos, tão prezados pela humanidade, nada mais são do que a estagnação, o congelamento desse elo palavra-coisa, sem ter a consciência de que inicialmente era tão somente o estímulo nervoso; outro ponto a considerar é que a palavra guarda uma referência às coisas empíricas que nomeia (LIMA, 2016).

A grande questão é saber: como esse estímulo sonoro que se forma no interior da subjetividade humana conquistou a posição de conceito universal? O que faz o humano ansiar por uma verdade? É o que trata o Fragmento Póstumo 19 [179], verão de 1872 - início de 1873 :

Quando se acredita possuir a verdade, a vida mais elevada e pura parece possível. A crença na verdade é necessária ao homem. A verdade vem à luz como necessidade social: por meio de uma metástase, ela é posteriormente aplicada a tudo aquilo que dela independe. Todas as virtudes nascem de carências. Com a sociedade, nasce a necessidade de veracidade. Do contrário, o homem viveria em eterno ofuscamento. A fundação do estado incita a veracidade. $\mathrm{O}$ impulso ao conhecimento tem uma origem moral (NIETZSCHE, [1872] 2008, p. 70, grifo nosso).

Segundo Nietzsche, a religião cristã com sua moral de ressentimento inventou a "grande estratagema" para aliviar a dor do homem ao responsabilizá-lo e culpabilizá-lo por seu sofrimento. Foi a forma de dar-lhe um sentido, pois o que o homem não suporta não é a dor, mas, sim, sua falta de sentido: “o homem preferirá ainda querer o nada a nada querer...” (NIETZSCHE, [1887] 2009, p. 140). Compaixão, culpa, conceitos de pecado e castigo são expressões dessa aspiração à "verdade".

Estimar o erudito e o impulso de conhecimento científico são sinais de doença, assim como a pretensão de determinar uma verdade absoluta. "Qualquer aliança com o erudito deve ser rejeitada. Esse é o maior inimigo, porque dificultam o trabalho dos médicos e negam a existência da doença"3. Para o filósofo alemão não há imparcialidade nessa dedicação à ciência - o anseio por essa verdade a ser "desvelada", representa a luta entre os próprios impulsos, mas numa mescla muito variada.

Nessa visão, os próprios conceitos, oriundos de uma "educação científica”, são metáforas e calcados na subjetividade. A verdade, portanto, pode ser uma ilusão, uma mentira "forjada" pelo próprio homem para dar conta da sua existência. Para o filósofo alemão, isso é impulsionado pela vontade de verdade4, uma busca sem

\footnotetext{
${ }^{3}$ Cf. Fragmento póstumo 29 [222] verão-outono 1872-1873, Nietzsche, v. 2, p. 549

${ }^{4}$ Nietzsche caracteriza a vontade de verdade de forma de negativa, mas também confere a ela um papel fundamental no raciocínio religioso ocidental: "o filósofo defende a seguinte relação lógica entre vontade de verdade e ateísmo: o ideal de probidade intelectual que constitui a vontade de verdade
} 
limites pela verdade e provém do mesmo pathos décadent dos ideais ascéticos contidos nas práticas religiosas. Nietzsche propõe pensar de forma extra-moral:

Pensar extra-moralmente certamente requer o abandono da posição em que se pensa moralmente. $\mathrm{O}$ discurso moral inaugurado por Sócrates, independentemente de suas variações ao longo de seu currículo, revela certos anseios metafísicos expressos em termos de imutabilidade, felicidade, imperturbabilidade, dignidade e negação da vida; a verdade, nesse caso, não concretiza uma aspiração puramente intelectual, mas serve primordialmente à vontade de conservação, com efeito, revela-se como meio de se escapar da transitoriedade, como fundamento imóvel para o refúgio da turbulência da vida. Nietzsche acusa Sócrates de ser o primeiro protagonista desse anseio metafísico, que oculta, por detrás dos seus disfarces conceituais, uma poderosa razão moral, que, em última instância, tende a imobilizar a vida (KRASTANOV, 2010, p.25).

\section{Verdade e Mentira em Freud}

Já Freud afirma que o fator determinante no modo como cada sujeito interpretará a sua vida tem por base uma fantasia, ou seja, uma "mentira". O psicanalista a princípio diferencia "fantasias ou devaneios conscientes" e "fantasia fundamental". O primeiro tipo são meios de satisfação substitutiva, um mero recurso para lidar com a frustração: "ficar devaneando sobre imaginárias realizações de desejo traz satisfação [...] idearam uma forma entre permanecer um animal a busca de prazer, e ser, igualmente, uma criatura dotada de razão" (FREUD, 1916-17, p. 374). O segundo tipo, a fantasia fundamental, é a que a psicanálise enfatiza pois é inconsciente e será responsável pela formação dos sintomas: "a libido retira-se para as fantasias, a fim de encontrar aberto o caminho que conduz a todas as fixações recalcadas" (p. 375). Para o autor, os relatos dos pacientes nem sempre são verdadeiros, alguns costumam ser o oposto direto da verdade histórica. Ele aponta que verdade e mentira são faces da mesma moeda: "As experiências recordadas na análise são, às vezes, indiscutivelmente falsas e às vezes, por igual, certamente corretas, e na maior parte dos casos são situações compostas de verdade e falsificação" (p. 369). Ocorre que "as fantasias possuem realidade psíquica, em contraste com a realidade material, e gradualmente aprendemos a entender que, no mundo das neuroses, a realidade psíquica é a realidade decisiva" (p. 370).

Assim, a realidade psíquica corresponde a uma realidade interna ao sujeito que é mediada por uma realidade externa, o que proporciona uma assimilação entre as representações do mundo exterior e interior. O sujeito tenderá a enxergar os acontecimentos de sua vida em termos de satisfação e/ou sofrimento sempre tendo por base essas "lentes próprias", que regulam sua relação com a realidade.

conduziria necessariamente à negação da "mais longa mentira" do Ocidente, isto é, a mentira da existência de Deus” (MELO NETO, 2016, p.427) 
O papel da fantasia no psiquismo é proporcionar uma satisfação que, se por um lado é negada na realidade, por outro continua a ser exigida pela pulsão. Dessa forma, uma tentativa de articular duas forças antagônicas - o princípio de realidade e o princípio do prazer.

Para Freud a necessidade de "fantasia/mentira", assim como o material que a fundamenta procede da pulsão. No texto Projeto de uma psicologia científica (1895), ele realiza uma decomposição da primeira experiência de satisfação e descreve o objeto inicial, supondo se tratar de outro ser humano, como sendo o primeiro objeto de satisfação pulsional. Esse “outro ser humano" será responsável pela ação específica de nutrir o recém nascido, pois "o organismo humano é, a princípio, incapaz de promover essa ação específica. Mas o que seria apenas a satisfação de uma necessidade [fome], no humano se mescla com uma satisfação sexual portanto pulsional. Uma vez já experienciada a satisfação, toda vez que reaparecer o "estado de urgência ou desejo" (p.371), haverá uma ativação concomitante entre a representação do objeto [lembrança] e a imagem, reconstruindo a presença do objeto a partir de uma alucinação. Esse é o argumento sobre a busca de objetos/situações que satisfaçam a pulsão. É o que fará o ser humano buscar uma satisfação mítica ao longo da vida.

Acompanhando Freud, Quinet (2012) destaca que a satisfação pulsional será sempre parcial, pois o objeto que supostamente traria a satisfação completa está perdido. Assim, as pulsões são investidas em diversos objetos que trazem satisfação momentânea, mas nunca ininterrupta. O ser humano procura constantemente este objeto que, um dia, trouxe uma suposta satisfação sem igual, uma plena satisfação. Isso ocasiona uma vida de procura e reencontros tão somente com substitutos fugazes. Assim, ele [o objeto] não está de volta, é somente uma sombra do que foi perdido sem nem mesmo ter existido. A satisfação é sempre mítica, fantasiosa e dará origem à noção freudiana de realidade psíquica. Isso significa que a verdade é uma ficção e que, portanto, toda mentira está "atravessada" pela verdade singular de cada um.

\section{Intersecções}

Considerando o que foi exposto até o momento, convém elucidar os pontos em que se cruzam as duas linhas de pensamento aqui abordadas - obviamente sem o intuito de que coadunem.

Tanto em Nietzsche quanto em Freud há uma interrogação sobre o que vem a ser a verdade. Freud afirma que toda a busca de sentido ao longo da vida está assentada em uma ficção - há uma falta total de sentido para a existência. É o encontro com esse nada que a neurose pretende evitar a todo preço (GODINOCABAS, 2009). Em Genealogia da Moral, Nietzsche (2009, p. 139) aponta que "algo faltava, que uma monstruosa lacuna circundava o homem - ele não sabia justificar, 
explicar, afirmar a si mesmo, ele sofria do problema do seu sentido. [...]o ideal ascético lhe ofereceu um sentido!".

$\mathrm{Na}$ direção do tratamento dos sintomas em Freud, espera-se que o sujeito mude sua relação com a fantasia. Ele propõe uma travessia/reconstrução da fantasia fundamental e chegar até ela é um ponto limite da análise - é o encontro com o rochedo da castração. Por castração entende-se a privação humana, sua falta de objeto. Essa ilusão [fantasia] de que haveria objeto capaz de proporcionar satisfação total é justamente que conduziu a interpretação pessoal que cada ser humano deu ao desfechos de sua própria vida.

A técnica freudiana de associar livremente considera: que a mentira está atravessada pela verdade singular de cada um, que as palavras não têm significado unívoco e que: aparecerão como Condensação (metáfora) ou Deslocamento (metonímia); de forma ambígua; não significam nada (imagem acústica) e não representam nada sozinhas; manifestam-se em cadeias associativas (condensadas e deslocadas); as palavras mostram e velam ao mesmo tempo, por isso podem ser "mentira" e "verdade" ao mesmo tempo - mentira em psicanálise não tem a acepção pejorativa ou moral.

Uma noção nietzschiana, já deduzível no texto "Verdade e Mentira", é o perspectivismo. O termo é frequente na década de 1880 e é utilizado pelos comentadores em diferentes contextos e funções. Mas para este escrito essa noção de "perspectiva" ou "ótica" coaduna com a ideia de que: não há conhecimento ou verdade em si. Mas é preciso construir a partir de uma determinada perspectiva, o que se chama de "mundo". "O que se chama "mundo", consiste em simplificação, falsificação, erro, ilusão, ficção, aparência. Mas é precisamente de um mundo perpectivístico que depende nossa conservação; sem ele, em todo caso, pereceríamos" (CORBENAZI, 2016, p.336).

Esse "conhecimento", produzido pela travessia da fantasia no processo analítico freudiano, não é um "conhecimento que se pretende verdade e muito menos é universal” - ele não serve a mais ninguém a não ser a si próprio e sem as amarras da ilusão/ideal. É uma perspectiva - não uma verdade unívoca e que pode a ser construída em análise - desmontar a sua ficção e também assentar em novas bases, saber da ilusão que os ideais de completude ou veracidade absoluta representam. Os escritos dos dois autores orbitam em torno da experiência da falta de sentido que o humano camufla, a proposta desse escrito é apenas iniciar o modo peculiar como concebem a articulação entre verdade e mentira, e como conduzem essas perspectivas.

\section{Referências}

CORBENAZI, E. Verbete: Perspectivismo [Perspektivismus]. In GEN. Dicionário Nietzsche. São Paulo: Loyola, 2016. 
FREUD, S. Projeto de uma psicologia científica [1895]. In: Edição Standart Brasileira das Obras Psicológicas Completas de Sigmund Freud. Vol. I. Rio de Janeiro: Imago, 1996.

. Conferência XXIII: Os caminhos da formação dos sintomas [1916-17]. In: Edição Standart Brasileira das Obras Psicológicas Completas de Sigmund Freud. Vol. XVI. Rio de Janeiro: Imago, 1996.

GODINO-CABAS, A. O sujeito na psicanálise de Freud a Lacan: da questão do sujeito ao sujeito em questão. Rio de Janeiro: Zahar, 2009.

KRASTANOV, S. V. Nietzsche: pathos artístico versus consciência moral. São Carlos: UFSCar, 2010. 131 f. Tese (Doutorado) -- Universidade Federal de São Carlos, 2010.

LIMA, J.S.L Verbete: Verdade [Wahrheit]. In GEN. Dicionário Nietzsche. São Paulo: Loyola, 2016.

MELO NETO, J. E. Verbete Vontade de verdade [Wille zur Wahrheit]. In GEN. Dicionário Nietzsche. São Paulo: Loyola, 2016.

NIETZSCHE, F.W. Sobre verdade e mentira no sentido extramoral. Tradução F. M. Barros. São Paulo: Hedra, 2012. [1887] Genealogia da moral: uma polêmica. Tradução P. C. de Souza. São Paulo: Companhia das Letras, 2009. Fragmentos Póstumos 1885-1889 (vol. II). Madrid: Editorial Trotta.

Submissão: 10.10.2018 / Aceite: 20.12.2019 